\title{
Do Haiti ao Planalto: os militares e a relação com a ONU no primeiro ano do governo Bolsonaro
}

\author{
Tales Campos
}

Resumo: O objetivo deste artigo é analisar as relações entre o governo Bolsonaro e a ONU em 2019 no âmbito da política externa - considerando a importância que a Missão das Nações Unidas para a Estabilização do Haiti (MINUSTAH) tem para as Forças Armadas (FFAA) e para a projeção internacional do Brasil. A metodologia utilizada neste artigo consiste em pesquisa bibliográfica relacionando materiais primários e secundários (teses, artigos e dissertações) com material jornalístico recente sobre a gestão federal. $\mathrm{O}$ resultado obtido por este artigo demonstra que, apesar da divergência entre setores do governo federal quanto aos rumos da política externa brasileira, devido a questões de realinhamento no plano internacional, a aproximação da viabilidade das relações com a ONU por meio das missões de paz não está presente nos planos do Executivo e das Forças Armadas, embora haja prestígio dos militares por esse tipo de operação.

\begin{abstract}
This article aims to analyze the relations between the UN and Bolsonaro government in 2019 in the scope of foreign policy - considering the importance that the United Nations Stabilization Mission in Haiti (MINUSTAH) has for the Armed Forces and the international projection of Brazil. The methodology used in this article consists of bibliographical research relating primary and secondary materials (theses, articles, and dissertations) with recent journalistic material on federal management. The result found in this article demonstrates that, despite the divergence between sectors of the federal government regarding the directions of Brazilian foreign policy, due to issues of realignment at the international level, the approximation of the viability of relations with the UN through peace missions it's not present in the plans of the Executive and the Armed Forces, although the military has prestige for this type of operation.
\end{abstract}


Durante os debates presidenciais de 2018, a política externa obteve destaque como um dos diversos temas eleitorais. Em contextos de outras votações populares, este interesse pelo tema não demonstrou ser muito comum no que diz respeito à política externa, a integração regional e as orientações diplomáticas brasileiras faziam parte destas discussões. Neste sentido, a candidatura de Jair Bolsonaro pelo Partido Social Liberal (PSL) buscou romper com o modelo de inserção internacional do Brasil que fora preconizado pela gestão do Partido dos Trabalhadores (PT) entre os anos de 2003 a 2016 (Casarões, 2019, pp. 1-2).

Ainda neste contexto, a categoria militar doméstica e externamente passaram a ser uma peça essencial na condução dos governos que ascenderam ao poder após 2016 - principalmente na gestão Bolsonaro, uma vez que diversos setores estratégicos para o desenvolvimento das ações federais possuem algum membro do Exército envolvido na chefia ou no grupo responsável pela condução do Estado (Penido, Rodrigues e Mathias, 2020).

Dos anos de vigência do PT no poder até a chegada de Bolsonaro, uma quantidade considerável dos militares que se tornaram peça central da engrenagem bolsonarista (como o General Augusto Heleno) (Penido, Rodrigues e Mathias, 2020) fizeram parte da missão de paz mais significativa para o Brasil nos anos 2000 e 2010: a campanha do Haiti, iniciada em 2004, como parte de um projeto de política externa do governo Lula. Ao obter o comando militar da Missão das Nações Unidas pela Estabilização do Haiti (MINUSTAH), os militares se aliaram a um esforço conjunto latino-americano e particularmente brasileiro de promover "paz e justiça social" a um país em um profundo estado de conflito, como afirmou o presidente Lula (Brasil, 2007, pp. 78-79).

Para alguns dos militares desta operação de paz como o Tenente General Floriano Peixoto, “a presença militar do Brasil no Haiti por 13 anos pode, sem dúvida, ser descrita como uma experiência épica que atingiu completamente todos os objetivos previstos por seus idealizadores em 2004" (Carrera Neto; Moraes, 2017, p. 16), sem contar com o passado de ampla participação do Brasil em pelo menos 15 das 17 missões de paz que foram criadas entre 1956 a 1989, durante a Guerra Fria (Bracey, 2011, pp. 315-316).

A partir deste cenário, este artigo busca analisar o distanciamento do Brasil com relação à Organização das Nações Unidas (ONU) na agenda de formulação da política externa do Governo Bolsonaro - considerando a relevância da MINUSTAH na projeção política das Forças Armadas (FFAA) e do Brasil internacionalmente.

A fim de responder tal indagação, este artigo se divide nas seguintes sessões: em primeiro lugar, uma retrospectiva conjuntural relacionada ao posicionamento dos militares na condução no Brasil entre 1985 a 2019. Em seguida, um breve histórico acerca da atuação das tropas do Brasil e no Haiti durante a operação de paz; e em terceiro lugar, a análise sobre a participação dos militares e da administração bolsonarista com relação à ONU e às missões de paz. E por último, a conclusão deste artigo. 


\section{A intervenção dos militares na política brasileira}

Tradicionalmente, em um Estado formalizado, a principal missão das FFAA é a de garantir a segurança nacional. Entretanto, a defesa dos Estados em termos bélicos sempre foi consolidada por meio da salvaguarda de fronteiras externas por militares, principalmente ao se considerar as eventuais investidas contra inimigos ou para defender pontos estratégicos (Huntington, 2000, pp. 815). No que concerne à presença dos militares brasileiros, esta pode ser compreendida a partir de outros pontos de vista. Eles são parte considerável da vida política nacional há muitos anos, assim como as eventuais intervenções na política sempre foram feitas levando em conta posicionamentos próprios da categoria e anseios de outras classes políticas relevantes.

De acordo com Oliveiros Ferreira (2000), é importante considerar como o período de intervenção dos militares no Brasil Imperial entre 1821 a 1869 ajuda a entender a formação interna que moldou o Exército ao longo dos anos. Enfrentamentos diretos a D. Pedro I no clarear da Independência e o apoio de um dos setores mais bem-consolidados secularmente no Brasil (a Igreja Católica) ajudaram a moldar o caráter nacional e a rebaixar o poder civil frente a pressões militares na política (Oliveiros Ferreira, 2000, pp. 39-96).

Atitudes que já anunciavam uma intervenção dos militares na política foram se tornando cada vez mais frequentes ao longo dos anos e levaram a uma condição que finalmente desembocou em 1964 - uma tomada do poder frente à crescente desconfiança no chefe do Executivo, resultando no rompimento do sistema político. Este golpe conduziria os rumos do Estado até encontrar um civil confiável e com chances de substituir os militares (Oliveiros Ferreira, 2000, pp. 39-96; Perlmutter, 1969, pp. 382-404).

Historicamente, entre os círculos oficiais durante o Império, construiu-se uma noção de que os militares seriam parte de um compromisso inabalável com o desenvolvimento nacional, defesa e patriotismo que, para eles, rege o Brasil. A noção de serem os "salvadores da pátria" levou muitos líderes desta categoria a acreditar em uma missão que consistia em neutralizar os inimigos, a fim de garantir a estabilidade do país. De tal maneira, buscar por tal estabilidade coincide até mesmo, na atuação em outros campos fora do setor bélico (Neto, 2019, pp. 13-17).

Com o retorno dos civis aos governos sul-americanos, os militares sofreram com sua imagem após o fim de suas atividades no poder. Ao mesmo tempo, uma dúvida permaneceu devido ao futuro democrático que resultaria da saída do Exército do Executivo. De acordo com a cientista política brasilianista Wendy Hunter (1995), os militares ficaram manchados pelo passado ditatorial - se tornando representantes do oposto à democracia. $O$ controle sobre o processo de transição entre o regime militar e a democracia ilustra este sentimento. A autora chega a questionar se os militares ainda possuíam um papel ativo em governos democráticos que foram sucessivamente retirando o poder desta classe (Hunter, 1995). Entretanto, de acordo com outros estudiosos, era cedo demais 
para confirmar que os militares haviam se tornado um simples "tigre de papel" (Zaverucha, 2001, pp. 31).

Por um breve período, o enquadramento dos militares à vida democrática com a fundação do Ministério da Defesa (MD) no final da década de 1990 seria para muitos o fim da pressão dos militares sob o rito popular. Entretanto, tal percepção foi breve (Zaverucha, 2001). Nos anos Lula e Dilma na presidência, os militares permaneceram relevantes na vida política do país. As ações envolvendo Garantias da Lei e da Ordem (GLO) demonstraram como o setor ainda estava envolvido nos eventos da política nacional. Por exemplo, 1.800 homens ligados ao setor de segurança em atividades de supressão do crime organizado foram convocados na operação do Complexo do Alemão e na Penha em 2010, sem contar com a presença brasileira no Haiti simbolizada pelos 32 mil homens que estiveram em operação na MINUSTAH (Mathias, Zague e Santos, 2019, pp. 136-168).

No governo Lula, a participação dos militares era uma forma de projetar influência do Brasil no sistema internacional. No governo Dilma, se esperava o mesmo. Por mais que tivesse sido presa e torturada durante o Regime Militar de 1964, a primeira mulher presidente era intensamente ligada ao seu mentor. A expectativa era que houvesse um governo de manutenção das políticas do líder petista (Mathias, Zague e Santos, 2019, pp. 136-168).

Contrariando o que era prometido, com Dilma a situação alterou-se de forma inesperada. Decisões incômodas como a presença de civis no controle da pasta da Defesa e a realização de investigações sobre o passado dos militares durante o regime de 1964 na Comissão Nacional da Verdade (CNV) soaram como uma ameaça aos seus interesses. Conforme os anos do Governo Dilma chegaram ao fim e o interregno Temer (2016-2018) começou, os militares ganharam espaço para realizar declarações e ocupar cargos em acordos entre governo e classe política. Por exemplo, o General Eduardo Villas Bôas encontrou um ambiente propício para opinar sobre a política nacional por meio de declarações no Twitter, o que rendeu críticas de determinados setores civis (Betim, 2018).

As respostas em razão de declarações veiculadas surgiram por meio dos mais diversos atores, seja nas redes sociais ou em público. Por exemplo, após as postagens feitas pelo General Eduardo Vilas Bôas em 2018 a respeito do habeas corpus durante o processo do ex-presidente Lula no Supremo Tribunal Federal (STF), a senadora do PT, Gleisi Hoffman, o governador do Maranhão, Flávio Dino, e diversas entidades ligadas à Ordem dos Advogados do Brasil (OAB) condenaram as declarações expressando preocupação e pedindo respeito ao processo judicial $(\mathrm{G1}, 2018)$.

Apesar das condenações a casos graves ou polêmicos, a emissão de opinião por membros do Exército não se restringe somente aos generais. Durante a campanha eleitoral de 2018, cerca de 220 publicações ou mensagens de tom político-partidário foram feitas por contas de usuários ligados às FFAA no Twitter, endossando apoio a candidatos ou criticando opositores e demais autoridades (Godoy, 2019). Todos estes fatores ajudam a fortalecer nos militares uma coalizão viva e consolidada com valores próprios e que cultivam uma visão pessoal de sociedade em diversos temas. Sendo 
assim, entre o corpo das FFAA, há uma inquietação constante sobre os rumos da política nacional, e que sempre estiveram presentes nos clubes militares (Oliveira, 1987, pp. 53-55).

Em relação ao uso da força nas missões de paz, há um aparente conflito entre os valores presentes na participação de uma política de peacebuilding em comparação com os ideais da política externa de um Estado. De acordo com Villa e Jenne (2020), é importante considerar que, para os países do Sul Global ou para os chamados "emergentes", utilizar de seu poder militar não é a primeira opção, favorecendo medidas de soft-power e que tenham maior influência sob a esfera multilateral como saída para opções que envolvam temáticas de cunho bélico. Desta forma, em termos de apoio às políticas de paz, estes Estados propõem um rompimento com as formas tradicionais de intervencionismo, enfatizando a presença de um forte quadro institucional seguido pela Organização das Nações Unidas (ONU) (Duarte Villa e Jenne, 2020, pp. 407-410).

Na percepção de Campos (2019), e particularmente no caso do Brasil, a mudança de posicionamento do país a favor de uma participação mais engajada do país em Missões de Paz da década de 1990 em diante tem relação tanto com mudanças nos rumos da política externa como nas decisões orçamentárias e administrativas. Se por um lado, a partir da inserção internacional pensada pela gestão Lula (2003-2010) foi possível optar por uma diplomacia voltada aos valores humanitários (o que se estendeu à forma como o país passou a experimentar suas operações de paz), por outro a expansão do orçamento militar nacional e as alterações nas estruturas normativas favoreceram para que o engajamento brasileiro passasse a ser muito maior do que nas participações anteriores (Campos, 2019, pp. 221-222).

Vale ressaltar que a presença engajada do Brasil nas missões de peacebuilding na última década contrasta com os rumos que definem a política externa brasileira e o posicionamento do país em relação à América Latina. Naturalmente, o Brasil se vê como um Estado pacifista, e no continente em geral, sua ingerência em outros países não ocorre há mais de um século, o que demonstra a ausência de inimigos próximos às suas fronteiras (com breves menções a potências extrarregionais como principal ameaça). Paralelamente, a presença de atores ligados ao crime organizado e ao narcotráfico se tornaram a principal preocupação em espaços como a Amazônia (Malamud e Alcañiz, 2017, pp. 1-15).

Neste quesito, e especificamente no caso do Haiti, é importante ressaltar que a experiência das FFAA em operações de paz representava um exercício para que as próprias classes militares buscassem a profissionalização de suas ações com base na semelhança de "terreno" entre Porto Príncipe e o Rio de Janeiro, visto como um guia para orientar o desenvolvimento de uma política Sul-Sul entre o Brasil e o Haiti, orquestrado pelas FFAA (Schuberth, 2019, pp. 487-491).

Por este motivo, a participação do Brasil em missões de paz em outros Estados como o Haiti é relacionada a uma nova fase de projeção internacional vivenciada pelo país desde meados da 
década de 1990. No próximo tópico, este artigo trabalhará o envolvimento do Brasil na Missão de Paz do Haiti, e seus desdobramentos ao longo de 13 anos de operações no país caribenho.

\section{A Operação de Paz do Brasil no Haiti (2004-2017)}

Antes da operação ser instituída em 2004, o Haiti passava por uma crise de instabilidade política que remonta à destituição do líder dos chimères $^{1}$ em 1991. Aristide era o chefe de Estado do país, enfrentando uma grave crise política interna. Vencedor do primeiro pleito popular ocorrido no país, o presidente já se encontrava em uma encruzilhada, iniciando uma série de reformas para investigar violações de direitos humanos dentro das corporações militares e policiais. Estas reivindicações eram feitas desde o fim da ditadura dos Duvalier ${ }^{2}$ (Corbellini, 2009, p. 96; Produr, 2012, p. 16). Em 2000, Aristide venceu o pleito com $92 \%$ de apoio da população, mas com apenas $5 \%$ de comparecimento da população votante, configurando fraude eleitoral. A fraude perpetrada pelo partido do presidente, o Famille Lavalasse (que teria conseguido 100\% das cadeiras do congresso) já havia ocorrido em uma eleição anterior que levou à dissolução do parlamento. Em razão destas circunstâncias, era necessário que em 2000, o congresso voltasse a ser uma estrutura de confiança institucional do presidente da república (Corbellini, 2009, p. 96-98; Produr, 2012, p. 16-20).

Antes da operação de paz ser consolidada, a Comunidade do Caribe (Caricom) tentou promover um acordo entre Aristide e os opositores, sem sucesso. Consequentemente, uma revolta de milícias antigovernistas se instalou no Haiti em fevereiro de 2004, levando Aristide a se exilar na África do Sul. O Chefe de Estado provisório, e presidente da Suprema Corte Boniface Alexandre pediu ajuda urgente à ONU. O Conselho de Segurança das Nações Unidas (CSNU), por meio da Resolução 1542, decidiu pela formação de uma Força Multinacional da Paz (FMP) pela estabilidade haitiana (Corbellini, 2009, pp. 96-100).

O Brasil recebeu a oferta de participar da operação de paz a partir do então Secretário-Geral, Kofi Annan, e do presidente francês, Jacques Chirac, para compor as forças que atuariam no país (Silva; Paula, 2017). Historicamente, o Brasil já havia participado de diversas missões de paz. Portanto, não era um fenômeno raro: entre 1956 a 1989, o Brasil participou de metade das operações. Esse percentual caiu entre 1989 a 2002, estando presente em 11 das 37 intervenções estabilizadoras (Bracey, 2011, pp. 315-320). Contudo, o Haiti foi a maior aventura militar que o país se envolveu nos últimos anos. A participação em operações deste porte fazia parte de um conjunto de planos e motivações que constituíam a política externa do Governo Lula (Bracey, 2011, pp. 315-320). Entre

1 Os apoiadores do presidente Aristide, deposto do Haiti em 2004 são conhecidos pela alcunha de chimères (Corbellini, 2009, pp. 96-101).

2 Francis 'Papa Doc' Duvalier (1957-1971) e Jean-Claude ‘Baby Doc' Duvalier (1971-1986) fazem parte do governo dos Duvalier, período ditatorial que se estendeu durante o Haiti entre os anos 1950 a 1980, deixando como legado mortes de dezenas de milhares de pessoas além de intensa repressão por meio da milícia pessoal "Tonton Macoutes" (Produr, 2012, pp. 16-26). 
um dos maiores objetivos, estava a chance de pleitear um assento permanente em uma eventual reforma do CSNU junto à Alemanha, Japão e Índia (Fontoura; Uziel, 2017, pp. 9-14).

Com a aprovação da participação brasileira na MINUSTAH pelo legislativo, a iniciativa do presidente Lula levou 1.200 homens das FFAA para o exterior, contabilizando 140 milhões de reais para seis meses de atuação no Haiti. Este primeiro contingente foi comandado pelo General Augusto Heleno Pereira (Silva; Paula, 2017, pp. 1-5). Além da pretensão de se tornar um representante sulamericano no CSNU, o segundo objetivo a ser atingido no Haiti era o de melhorar a relação entre o MD e o Ministério das Relações Exteriores (MRE). Esta seria a oportunidade para os militares estabelecerem uma relação mais próxima com o Itamaraty nos planos diplomáticos do Governo Lula (Bracey, 2011, p. 16-26).

A operação no Haiti tinha como trunfo este "lado brasileiro" de sensibilidade e de aproximação cultural com a população local, o que permitiria ao país agir de forma diferenciada frente a outras missões de paz protagonizadas por Estados do norte global (Muller; Steinke, 2018, pp. 228-249). Porém, os erros cometidos pela administração brasileira no Haiti são semelhantes aos de outras missões de paz. As falhas foram em várias áreas durante e após o fim da MINUSTAH. A primeira foi com relação à própria Polícia Nacional Haitiana (PNH), uma vez que as operações policiais haitianas agiram exagerando no uso da força- inclusive promovendo execuções sumárias contra civis. A barreira linguística entre militares da ONU e policiais também foi motivo de discordância entre os dois lados (Zanini, 2019). Além dos problemas estruturais, os militares também utilizaram força excessiva:

O mesmo soldado "que usa força letal é o mesmo cara que presta assistência humanitária". Isso promove uma melhor interação com a população. A população já sabe que esse esquadrão específico ou soldado quando ele usa força e o percebe como [faz uso da força] (...) "ah, ele usa a força letal porque ele não tinha outra escolha". Então, isso melhora o entendimento ou a "acceptance" (Muller; Steinke, 2018, p. 235).

Além disso, ocorreram casos de abuso sexual durante a missão de paz, causando revolta e repúdio entre a população civil. Diferente do que era veiculado por tropas da MINUSTAH a operação proposta era diferenciada, foram noticiados casos de estupro ou de abuso envolvendo tropas uruguaias e brasileiras. Os soldados foram repatriados e não foram julgados por suas atitudes, por mais que estes soldados devessem ser devidamente punidos. Nestes casos, a ONU não possui poder para ponderar sobre tais acontecimentos. Somente entre 2007 a 2010, foram 141 relatos de abuso sexual ou de exploração por membros da MINUSTAH (Amaral; Viana, 2011a).

Apesar dos problemas causados pelas atitudes dos soldados em território estrangeiro, a MINUSTAH também conseguiu fazer do Haiti um laboratório de testes para um Estado cuja experiência prévia em lidar com grupos criminosos no Rio de Janeiro já era um fator diferencial. As 
ações incorporadas a partir da instalação das Unidades de Polícia Pacificadora (UPP) em 2008, além de uma série de medidas de ação interna desenvolvidas pelo MD, como as políticas de GLO foram absorvidas de práticas do Exército Brasileiro no exterior. Para muitos policiais e militares, o Haiti demonstrava como o modelo de aproximação da população que se utilizava no Brasil poderia ser bem sucedido internacionalmente (Muller; Steinke, 2018, pp. 228-249). No cenário político, a presença dos militares com experiência no Haiti ecoou nos anos seguintes da política brasileira. Uma vez definidos estes fatores de debate, o próximo tópico irá discutir a presença massiva dos militares na vigência do Governo Bolsonaro, os fatores que alimentam a atuação do Exército nos cargos administrativos de Brasília a partir da eleição do capitão reformado, a política externa brasileira e o seu envolvimento com a ONU.

\section{A relação militar-onusiana nos tempos bolsonaristas}

Em relação às Missões de Paz, é inegável o protagonismo das FFAA brasileiras em operações tanto no âmbito da ONU como da Organização dos Estados Americanos (OEA). O tamanho da participação e do efetivo brasileiro é significativo em esforços, sendo que já integraram missões no Timor-Leste, Moçambique, e no Haiti (Oliveira et al., 2019). No entanto, desde o impeachment da presidente Dilma em 2016 que os planos de novas atuações do Brasil em missões de paz diminuíram drasticamente. Em 2017, o Brasil recusou o convite para participar da Missão Integrada Multidimensional de Estabilização das Nações Unidas na República Centro-Africana (MINUSCA) alegando problemas orçamentários e administrativos (Oliveira et al., 2019).

Da transição de Temer para Bolsonaro, o posicionamento conjuntural quanto às atividades do Brasil no exterior demonstra um caráter de continuação. Algumas áreas onde o governo brasileiro costumava fomentar articulações que justificavam sua participação em operações de paz no exterior foram colocadas de lado. As duras declarações a ONU somado aos cortes orçamentários promovidos pelo Brasil (Oliveira et al., 2019) colocam o país em um ambiente que não incentiva sua participação nos maiores empreendimentos no qual as FFAA costumavam se envolver no âmbito das Nações Unidas.

Ainda assim, é necessário destacar os próprios interesses militares em participar de missões de paz no cenário brasileiro. De acordo com David Pion-Berlin (2012), muitos Exércitos são colocados à prova em Operações de Manutenção de Paz (OMP) e em boa parte dos casos, aprendem a tomar ações que não são de seu campo, capacitando-os para novas missões e reformulando os objetivos das tropas no cenário interno e externo. Para o autor, a tendência das FFAA convocadas ou convidadas a participar depende do grau de comprometimento em realizar missões de tal porte. Ao decidir pelo cumprimento dessas missões, a categoria militar integralmente concorda com os ganhos técnicos assumindo a responsabilidade das ações. Entretanto, também podem ocorrer reações 
adversas que podem sinalizar contrariedade ou desacordo com relação a determinações do Estado (Pion-Berlin, 2012, pp. 627-643).

Se para aspectos profissionais e operativos, as missões de paz são atrativas para o corpo militar, domesticamente estas ações de cunho geopolítico não costumam ter impacto sobre a popularidade dos militares. Desta forma, as FFAA variam entre aceitar e negociar a participação em uma missão de paz (Pion-Berlin, 2012, pp. 627-643).

No caso das FFAA brasileiras e sua relação com as Missões de Paz, na percepção do próprio General Augusto Heleno, o aprendizado no Haiti foi uma experiência não só positiva, como também originou em um conhecimento de combate inédito para mais de 23 mil militares, indicando uma grande chance de ascensão na carreira profissional. Por exemplo, Heleno destaca que a participação na MINUSTAH gerou uma disputa burocrática entre os militares por promoções, buscando atingir cargos superiores na carreira. Todavia, a transformação deste capital em novas operações de peacebuilding com a presença de tropas brasileiras contrasta com visões dos membros da classe sobre os ganhos econômicos, diplomáticos, estratégicos e conjunturais (Castro; Marques, 2019, pp. 47-49).

Por exemplo, após o Haiti, na ocasião que avaliava a possibilidade do Brasil integrar as forças de atuação na República Centro-Africana, a posição dos militares foi dividida: parte do efetivo era a favor de integrar novas missões, enquanto a outra parte acreditava que era necessário em primeiro lugar resolver os problemas internos (Oliveira et al., 2019).

Neste caso, pode-se considerar que o posicionamento militar perpetrado pelos ex-Force Commanders brasileiros em relação a participação nas Missões de Paz depende de um cálculo racional e analítico (influenciado pela burocracia nacional simbolizada pelo Executivo) no qual a proposta de participar de uma futura atuação no exterior junto às Nações Unidas se torna, de fato, rentável às FFAA. Portanto, se por um lado, na cúpula militar, havia um certo ânimo em protagonizar novas missões junto à ONU, por outro, se questionava se o Brasil tinha um objetivo estratégico a cumprir dentro de sua área de influência em uma nova operação no exterior (Uziel; Marcondes, 2021, pp. $762-768)$.

Por exemplo, para o General Santos Cruz, a situação vivenciada pelo Brasil em 2018 era diferente do contexto em solo haitiano. O general salienta que, em primeiro lugar, em sua opinião, o comércio existente o Brasil e a República Centro-Africana eram pouco significativos para justificar uma futura missão na época. A atuação somente seria positiva em termos de acesso a mais orçamento para operações e profissionalização da tropa. Neste último ponto em específico, as ideias de Augusto Heleno e Santos Cruz convergem (Castro; Marques, 2019, pp. 106-107).

Acima de outros fatores, é primordial apontar que, entre as escolhas preferenciais do comando militar brasileiro, a República Centro-Africana era a terceira opção já que Chipre e Líbano não necessitavam de tropas terrestres (Uziel; Marcondes, 2021, pp. 762-768). O Itamaraty alertava 
que, em termos de desafio operacional, uma intervenção onusiana com eventual auxílio brasileiro no caso de um país como a República Centro-Africana situaria as tropas em uma encruzilhada entre rebeldes cristãos e muçulmanos, levando o efetivo a agir para conter os impulsos dos dois lados, a fim de estabilizar o país. Esta situação certamente colocaria as tropas brasileiras em rota de colisão entre os dois lados desta guerra civil (Giuliano; Moraes, 2019, pp. 257-274).

Além disso, Santos Cruz destaca que, entre as guerrilhas situadas no país, havia uma ausência de objetivos ou propostas de governo a fim de resolver as animosidades locais. Desta forma, o custo humano em uma missão sem quaisquer perspectivas de estabilidade futura se tornaria infrutífero: "Só que tem uma coisa: aí morrem três ou quatro lá, você vai justificar aqui como? Você foi para lá com qual objetivo?" (Castro and Marques, 2019, pp. 108-109). Em termos financeiros, uma missão desta exigiria maiores gastos orçamentários para auxiliar as tropas a desenvolver suas estratégias em um Estado com infraestrutura mais deficiente do que o Haiti (Giuliano; Moraes, 2019, pp. 257-274).

Neste cenário sobre a adesão ou não do Brasil à MINUSCA, havia uma dualidade de posicionamentos entre o quadro diplomático brasileiro (representados, por um lado, pelo Itamaraty) e o efetivo militar em contato com a ONU (caso de determinados militares alocados dentro do Ministério da Defesa).

No fim das contas, o que fez o MD recuar foi o fator orçamentário: em 2017, calculava-se que o envio de 750 tropas brasileiras custaria cerca de R\$ 400 milhões. Considerando a situação econômica do país, era insustentável manter um número elevado de soldados perante valores tão altos, e a resistência das FFAA em participar por meio de um efetivo menor e mais barato eliminou qualquer possibilidade de futura participação militar brasileira (Uziel; Marcondes, 2021, pp. 771773). Se para o horizonte temporal brasileiro, a possibilidade de participação das missões de paz não enfrentava entraves perante a saída do Brasil do Haiti, o engajamento em uma eventual participação numa missão de paz por meio da plataforma da ONU não parece tão clara tanto para o Governo Bolsonaro como para as FFAA.

A relação de Bolsonaro com as FFAA tem um caráter intimamente histórico e por consequência eleitoral frente às suas demandas populares no tocante à melhoria da qualidade do serviço militar. Bolsonaro e os militares também possuem semelhanças em determinados aspectos ideológicos. O capitão reformado e alguns membros do seu corpo executivo como o seu vice, Hamilton Mourão, e o chefe do Gabinete de Segurança Institucional (GSI), Augusto Heleno, fazem parte de uma geração militar formada nos últimos anos da Ditadura, ao final dos anos 1970 e início dos anos 1980. Na percepção desta geração, o evento que originou o golpe de 1964 foi apoiado pelas classes populares e supostamente tinha como objetivo evitar o alinhamento brasileiro por parte do presidente João Goulart ao comunismo internacional. Para esta última geração formada na Ditadura, 
práticas violentas como a tortura, o cerceamento de liberdades da população e a morte de opositores sempre foram ignoradas ou negadas (Gielow, 2020).

Dentro do governo Bolsonaro, o status das FFAA de técnicos e moderados teria levado a categoria a agir para impor a moralidade dentro das ações governistas. Mesmo assim, ao longo do primeiro ano da gestão, o posicionamento de moderação que foi dado ao Exército em algumas ocasiões foi colocado em xeque por declarações exaltadas de alguns de seus representantes (Penido, Rodrigues e Mathias, 2020). Apesar do alinhamento de ideias e do perfil próximo e simpático ao corpo das FFAA, a relação de Bolsonaro com a ONU se limitava ao desprezo e críticas constantes.

Ao longo da trajetória do governo brasileiro, diversas declarações constatam a revolta que a ONU traz à política externa de Jair Bolsonaro. O assessor especial da presidência da república, Filipe Martins, declarou em fevereiro de 2020 que o Itamaraty servia pura e simplesmente aos interesses das Nações Unidas, o que causou incômodo no corpo diplomático brasileiro (Gielow, 2020a). O próprio Bolsonaro no decorrer da campanha expressou críticas e desacordos quanto ao modo de funcionamento da ONU e seu posicionamento no cenário internacional, chegando até mesmo a ameaçar uma eventual saída do Brasil da organização (Oliveira et al., 2019). O motivo deste comportamento combativo do Bolsonaro tem relação com a forma como a inserção internacional do Brasil foi pensada dentro de sua gestão.

A política externa do governo Jair Bolsonaro se baseia desde sua formulação em previsões e aconselhamentos do bolsonarista Olavo de Carvalho, alterando em determinados segmentos a forma como o Brasil se posicionava no sistema internacional. Diversas características podem ser utilizadas para classificar esta política externa do "novo Brasil" - podendo ser essencialmente nacionalista, anti-globalista ou simplesmente conservadora (Casarões, 2020). Vale ressaltar que o fenômeno olavista não é um programa isolado em torno dos apoiadores do governo. De acordo com Leirner (2020), a divisão entre as alas que regem as políticas do governo não é tão clara, de tal forma que, entre parte do efetivo do MD, militares fazem uso do discurso "olavista" com o objetivo de produzir respostas contundentes e ganhos para a categoria. Para o autor, tudo se trata de uma estratégia com o objetivo de enriquecer o MD (Leirner, 2020, pp. 255-301; Instituto Humanitas Unisinos, 2020).

Esta política externa segue pelo menos três formalidades: a rejeição completa a qualquer posicionamento ou projeto que se relacione a política externa dos governos Lula ou Dilma (simbolizado pelo enfrentamento ao regime venezuelano no campo diplomático), a busca pela reaproximação com parceiros-chave no cenário internacional (Estados Unidos, Israel e Itália) e o antiglobalismo como linha de pensamento central do Brasil no cenário externo, indicando alinhamento ao Ocidente e a proteção de valores como pátria, Deus e o núcleo familiar tradicional. Por este motivo que organizações multilaterais como a ONU e a União Europeia (UE) são consideradas órgãos financiadores do globalismo (Casarões; Flemes, 2019, pp. 1-13). 
Em termos documentais, há parcas evidências militares que aproxime o Brasil às Nações Unidas a partir do ponto de vista das operações de paz. Por exemplo, o Plano Nacional de Defesa (PND) e a Estratégia Nacional de Defesa (END) de 2020 destacam que devido às circunstâncias de insegurança no cenário internacional, as FFAA continuam dispostas a participar de missões de paz organizadas e orquestradas pela ONU, desde que coincidam com os interesses da política externa brasileira (Brasil, 2020).

Sendo assim, a ONU é uma plataforma distante (ainda que conjuntural ou protocolar) para os formuladores do pensamento militar na gestão Bolsonaro. Vale ressaltar que estes planos entram em conflito com a reformulação administrativa da política externa brasileira a serviço do Ocidente a fim de evitar a expansão do globalismo, conforme afirmava o ex-ministro Ernesto Araújo. Este seria um reposicionamento voltado ao campo ideológico (Saraiva; Silva, 2019, pp. 117-137). Todavia, o presidente foi protocolar com a possibilidade de integrar outras missões de paz com apoio brasileiro junto à ONU, conforme afirmou em seu discurso:

A devoção do Brasil à causa da paz se comprova pelo sólido histórico de contribuições para as missões da ONU. Há 70 anos, o Brasil tem dado contribuição efetiva para as operações de manutenção da paz das Nações Unidas. Apoiamos todos os esforços para que essas missões se tornem mais efetivas e tragam benefícios reais e concretos para os países que as recebem. Nas circunstâncias mais variadas - no Haiti, no Líbano, na República Democrática do Congo -, os contingentes brasileiros são reconhecidos pela qualidade de seu trabalho e pelo respeito à população, aos direitos humanos e aos princípios que norteiam as operações de manutenção de paz. Reafirmo nossa disposição de manter contribuição concreta às missões da ONU, inclusive no que diz respeito ao treinamento e à capacitação de tropas, área em que temos reconhecida experiência (Verdélio, 2019).

Desta forma, Bolsonaro e os militares convergem em alguns temas, não necessitando de intervenções por parte do MD a fim de retificar declarações que possam originar em danos materiais ou financeiros. Nestes casos em que as opiniões presidencial e militar são as mesmas, Vidigal (2019) considera que, acima das aspirações nacionalistas e desenvolvimentistas que definem $o$ comportamento militar, o que têm se fortalecido como objetivo final nesta categoria são os ganhos “corporativos, financeiros e políticos" (Vidigal, 2019, p. 8).

Por exemplo, é notável que o orçamento de Defesa do Brasil aumentou consideravelmente desde o fim da MINUSTAH em 2017. Durante aquele período, o MD recebeu R \$69,93 bilhões para o setor sendo que aproximadamente $\mathrm{R} \$$ 9,12 bilhões foram alocados para defesa nacional. No primeiro ano da gestão Bolsonaro, a Defesa recebeu $\mathrm{R} \$$ 85,16 bilhões, e $\mathrm{R} \$$ 9,23 bilhões para defesa nacional. Em contraposição ao aumento do orçamento, a fatia da Defesa voltada ao setor de cooperação internacional sofreu uma queda acentuada de 2017 a 2019 (de aproximadamente $\mathrm{R}$ 99,5 milhões para $\mathrm{R} \$ 64,8$ milhões) (Brasil, 2019, 2017). Este detalhe chama muito a atenção perante o perfil que constituiu o primeiro ano da gestão do presidente Bolsonaro. 
Com a ausência de uma sinalização mais clara de qual seria o objetivo que esta gestão teria em relação com a ONU ou em relação à futuras operações de paz, a presença dos militares dentro do corpo administrativo deste governo aponta para uma necessidade de preservar os ganhos econômicos na associação com a estrutura erigida pela gestão Bolsonaro (Oliveiros Ferreira, 1987, pp. 39-90).

Portanto, é possível considerar que, dentro do posicionamento das FFAA, o objetivo principal das castas militares é se firmar como parte integral do governo Bolsonaro, e das administrações vindouras. Por mais que tenham divergências internas dentro do corpo militar, este novo posicionamento fortalecido desde que as manifestações de generais se tornaram mais comuns, unificou as FFAA em torno de uma opinião em comum. Conforme os desdobramentos institucionais civis são definidos, a classe assentiria ou negaria apoio a determinados projetos que forem de seu interesse (Saraiva; Silva, 2019, pp. 117-137; Oliveiros Ferreira, 1987, pp. 39-90).

Desta forma, para Martins (2019), especificamente a partir da escalada crescente de oficiais em posições administrativas dentro do governo Temer, desembocando no governo Bolsonaro, havia um apelo público pela presença das FFAA como forma de estabilizar o Brasil após o impeachment da presidente Dilma, cuja característica comum era salvaguardar o país de ameaças urgentes à sociedade como o crime organizado e a corrupção, personificada pela gestão petista. Neste quesito, figuras como Hamilton Mourão e Villas Bôas encarnam este discurso (Filho, 2019).

Porém, para o autor, as FFAA não escaparam das polêmicas e confrontações ocasionadas no decorrer do primeiro ano da gestão bolsonarista (Filho, 2019, pp. 174-175). Neste sentido, a utilização da força perante o governo Bolsonaro e a possibilidade de aproximação com a ONU passou a ser confrontada ideologicamente por uma política externa combativa contrária às organizações internacionais. Concomitantemente, no caso dos militares, enquanto uma parte integrante do governo, o foco incidiu mais na realização de atividades domésticas voltadas a GLO em contraposição à projeção militar no exterior como no Haiti (Aguilar; Mendonça, 2021, pp. 163190).

De acordo com Aguilar e Mendonça (2021), para compreender esta apatia frente às Nações Unidas, é preciso considerar que o pacto por uma política externa multilateral e participativa evocada pelos governos FHC e Lula sofreu um grande abalo na administração Dilma (2011-2016), sendo finalmente rompida com Temer e Bolsonaro. No fim das contas, com o encerramento deste modelo de atuação em 2019, sobrou às FFAA a manutenção da ordem social e o auxílio à população local (Aguilar; Mendonça, 2021, pp. 163-190).

Para que houvesse continuidade de medidas que fomentem a cooperação com a ONU, a exemplo das missões de paz, seria necessário maior engajamento brasileiro para manter o ativismo e evitar um distanciamento da organização. Por mais que haja, ainda que de forma protocolar por parte do presidente Bolsonaro e dos diversos documentos emitidos pelos órgãos de Defesa, a 
possibilidade de aproximação junto à ONU por meio das missões de paz enfrenta, acima das questões financeiras, a ausência de uma agenda própria que direcione os gastos nestes planos. (Campos, 2019, pp. 218-233).

\section{Conclusão}

Os militares estão inseridos na vida política brasileira muito antes de Bolsonaro. Sua presença é secular, assim como sua formação que remonta aos tempos imperiais. Devido a tal histórico, o envolvimento tanto em assuntos internos como externos se tornou parte das ações dos militares no governo. No caso das Nações Unidas, os militares foram centrais para que o Brasil se firmasse no plano exterior por meio das missões de paz - principalmente no caso da MINUSTAH. Apesar dos avanços e das críticas quanto ao modo de atuação "diferenciado", o Haiti certamente foi uma experiência marcante para a contemporaneidade das FFAA. Por este motivo, a ONU ainda demonstra ser objeto de atenção para muitos generais. Ainda assim, em prol da harmonia do "Partido Fardado", optou-se por controlar os ânimos frente a novas movimentações nas Nações Unidas após o sucesso militar do Haiti.

Contrário ao engajamento externo, o que imperou é somente uma visão dentro do governo Bolsonaro ao longo de 2019 - distanciamento, negação de conselhos e críticas agressivas a esta instituição. Em relação à possibilidade de participação em missões de paz, o papel protocolar se manteve, por mais que a hostilidade do governo brasileiro e a ausência de planos nacionais voltados ao tema barrem qualquer possibilidade de participação em alguma missão de paz, impedindo a aproximação entre o governo Bolsonaro e a ONU.

O realinhamento de metas e de objetivos em termos de desdobramento das FFAA demonstra ser o que prevalece na maneira como a caserna militar age dentro do papel de garantidor da estabilidade e obstinado em conter os distúrbios sociais no Brasil. Desta forma, o horizonte militar dentro das Nações Unidas aparenta ser inexistente neste momento. Vale ressaltar que, levando em conta o cenário de reformulação e de moderação que os militares foram colocados enquanto alicerce do governo federal, a ONU não é o assunto de maior preocupação em um grave período doméstico assolado pela pandemia, o que certamente desgastou não só a imagem do governo, mas também dos militares enquanto patrocinadores deste projeto nacional iniciado em 2019. A situação distancia ainda mais o Brasil de uma eventual projeção exterior orquestrada pelas FFAA, enquanto responsáveis pela manutenção da ordem do Estado.

\section{Referências}

Aguilar, S., Mendonça, T., 2021. Brasil e Forças Armadas: dissuasão, política externa e emprego interno. Colomb. Int. 107, 163-190. Disponível em: https://doi.org/10.7440/colombiaint107.2021.07. (Acessado: 18 novembro 2021). 
Campos, Tales. Do Haiti ao Planalto: os militares e a relação com a ONU no primeiro ano do governo Bolsonaro.

Amaral, M. Viana, N. (2011). 'Parte III: Mais abusos, menos punições'. Agência Pública. 27 setembro [online]. Disponível em: https://apublica.org/2011/09/parte-iii-mais-abusos-menos-punicoes/. (Acessado: 20 julho 2020).

Betim, F. (2018). ‘Do general Villas Bôas à reserva, a ofensiva dos militares que querem voz na política'. El País Brasil, 04 abril [online]. Disponível em:

https://brasil.elpais.com/brasil/2018/04/02/politica/1522697550_276313.html. (Acessado: 27 março 2020).

Bracey, D. (2011). 'O Brasil e as Operações de Manutenção da Paz da ONU: Os Casos do Timor Leste e Haiti'. Contexto Internacional. 33(2), p. 315-331. Disponível em:

https://www.scielo.br/j/cint/a/k6YfCdgfSZTvYk4jVpsKFgp/?lang=pt\&format=pdf. (Acessado: 09 junho 2021).

Brasil (2020). Ministério da Defesa. Política Nacional de Defesa e Estratégia Nacional de Defesa [online]. Disponível em: https://www.gov.br/defesa/pt-br/assuntos/copy_of_estado-e-defesa/pnd_end_congresso_.pdf. (Acessado: 27 julho 2020).

Brasil (2007). Ministério das Relações Exteriores. Secretaria de Planejamento Diplomático. Repertório de política externa: posições do Brasil [online]. Disponível em: http://funag.gov.br/loja/download/388Repertorio_de_PolItica_Externa_Posicoes_do_Brasil.pdf. (Acessado: 09 junho 2020).

Campos, L. M. C. L. (2019). 'A participação brasileira nas missões de manutenção da paz da ONU e os posicionamentos do novo governo'. Revista de Estudos Internacionais, 10(3), p. 218-233. Disponível em: http://www.revistadeestudosinternacionais.com/uepb/index.php/rei/article/view/499/499\#. (Acessado: 12 julho 2020).

Carrera Neto, S. Morais, M. (2017). 'Analysis of the Brazilian police's participation in MINUSTAH' [online]. in HAMANN, Eduarda Passareli. TEIXEIRA, Carlos Augusto Ramires (eds.). Brazil's participation in MINUSTAH (2004-2017): perceptions, lessons and practices for future missions. $1^{\text {st }}$ ed. Rio de Janeiro: Igarapé Institute, p. 66-75. Disponível em: https://igarape.org.br/wp-content/uploads/2018/03/BrazilsParticipation-in-MINUSTAH-2004-2017.pdf. (Acessado: 10 junho 2021).

Casarões, G. (2019). ‘Eleições, política externa e os desafios do novo governo brasileiro'. Pensamento Próprio, 24, p. 231-274.

Casarões, G.; Flemes, D. (2019). ‘Brazil First, Climate Last: Bolsonaro's Foreign Policy'. GIGA Focus. 5, p. 1-13. Disponível em: https://pesquisa-eaesp.fgv.br/sites/gvpesquisa.fgv.br/files/arquivos/brazil_first.pdf. (Acessado: 09 junho 2021).

Casarões, G. (2020). 'Política externa sob Bolsonaro e Ernesto Araújo inaugura a diplomacia populista'. Folha de São Paulo. 22 abril [online]. Disponível em: https://www1.folha.uol.com.br/mundo/2020/04/politicaexterna-sob-bolonaro-e-ernesto-araujo-inaugura-a-diplomacia-populista.shtml. (Acessado: 27 julho 2020).

Castro, C., Marques, A., (2019). Missão Haiti: a visão dos force commanders. Rio de Janeiro: FGV Editora, p. 7247. Disponível em: https://br1lib.org/book/5554672/5d5d14/?wrongHash. (Acessado: 11 novembro 2021).

Corbellini, M. D. (2009). Haiti: da crise à MINUSTAH. Universidade Federal do Rio Grande do Sul [online]. Disponível em: https://www.lume.ufrgs.br/bitstream/handle/10183/17674/000721343.pdf?sequence=1. (Acessado: 09 junho 2021).

Duarte Villa, R., Jenne, N., 2020. By all necessary means? Emerging powers and the use of force in peacekeeping. Contemporary Security Policy, 41, 407-431. Disponível em:

https://doi.org/10.1080/13523260.2019.1698691. (Acessado: 09 novembro 2021). 
Filho, J.R.M., 2019. Ordem desunida: militares e política no governo Bolsonaro. Perseu: história, memória e política, 18, 168-193. Disponível em: http://revperseu.fpabramo.org.br/index.php/revistaperseu/article/view/320/262. (Acessado: 18 novembro 2021).

Fontoura, Paulo Roberto C. T.; Uziel, Eduardo. (2017). MINUSTAH, ‘Brazil and the United Nations Security Council'. in Hamann, Eduarda Passareli. Teixeira, Carlos Augusto Ramires (eds.). Brazil's participation in MINUSTAH (2004-2017): perceptions, lessons and practices for future missions. $1^{\text {st }}$ ed. Rio de Janeiro: Igarapé Institute, p. 66-75. Disponível em: https://igarape.org.br/wp-content/uploads/2018/03/BrazilsParticipation-in-MINUSTAH-2004-2017.pdf. (Acessado: 10 junho 2021).

G1 (2018). 'Afirmação de comandante do Exército em rede social causa mal-estar'. 04 abril. Disponível em: http://g1.globo.com/jornal-nacional/noticia/2018/04/afirmacao-de-comandante-do-exercito-em-redesocial-causa-mal-estar.html. Acessado em: 10 outubro 2020.

Gielow, I. (2020a). 'Assessor de Bolsonaro diz que Itamaraty era 'escritório da ONU' e gera mal-estar'. Jornal do Brasil. 25 fevereiro [online]. Disponível em: https://www.jb.com.br/pais/politica/2020/02/1022442assessor-de-bolsonaro-diz-que-itamaraty-era--escritorio-da-onu--e-gera-mal-estar.html. (Acessado: 27 julho 2020).

Gielow, I. (2020). 'Ditadura formou geração de militares que hoje povoam governo Bolsonaro'. Folha de São Paulo. 27 junho [online]. Disponível em: https://www1.folha.uol.com.br/poder/2020/06/ditadura-formougeracao-de-militares-que-hoje-povoam-governo-bolsonaro.shtml. (Acessado: 25 julho 2020).

Giuliano, M.; Moraes, G.F. (2019). ‘O Brasil nas missões de paz depois da MINUSTAH: reflexões'. in Braga, C.C.V. Ferreira, A.C. (eds.). 13 anos do Brasil na MINUSTAH: lições aprendidas e novas perspectivas. Rio de Janeiro: Centro de Instrução Almirante Sylvio de Camargo, p. 257-274. Disponível em: https://igarape.org.br/wp-content/uploads/2019/11/livrosemhaiti13.pdf. (Acessado: 11 outubro 2020).

Godoy, M. (2019). 'Exército enquadra tuítes polêmicos de militares da ativa'. O Estado de São Paulo. 20 julho [online]. Disponível em: https://politica.estadao.com.br/noticias/geral,exercito-enquadra-tuites-politicosde-militares-da-ativa,70002930364. (Acessado: 10 outubro 2020).

Hunter, W. (1995). 'Politicians against Soldiers: Contesting the Military in Postauthorization Brazil'. Comparative Politics, 27(4), p. 425-443.

Huntington, S.P. (2000). The Soldier and the State: The Theory and Politics of Civil-Military Relations. $15^{\text {th }}$ ed. Cambridge: Harvard University Press, p. 1-97.

Instituto Humanistas Unisinos (2020). ‘Bolsonaro tem papel de 'causar explosão' para permitir ação 'reparadora' de militares, diz antropólogo'. Instituto Humanitas Unisinos, 08 jun [online]. Disponível em: http://www.ihu.unisinos.br/78-noticias/599745-bolsonaro-tem-papel-de-causar-explosao-para-permitiracao-reparadora-de-militares-diz-antropologo. (Acessado: 16 dezembro 2020).

Leirner, P.C. (2020). O Brasil no espectro de uma guerra híbrida: militares, operações psicológicas e política em uma perspectiva etnográfica. São Paulo: Alameda, p. 255-301.

Malamud, A., Alcañiz, I., 2017. Managing Security in a Zone of Peace: Brazil's Soft Approach to Regional Governance. Rev. bras. polit. int. v. 60. Disponível em: https://doi.org/10.1590/0034-7329201700102. (Acessado: 11 novembro 2021).

Mathias, S.K.; Zague, J.A.; Santos, L.F.S. (2019). 'A política militar brasileira no governo Dilma Rousseff: o discurso e a ação'. Opinião Pública - Revista da CESOP, 25(1), p. 136-168. Disponível em: https://www.scielo.br/j/op/a/7CrYtjxqpVbDWkj6W63gfJF/?lang=pt\&format=pdf. (Acessado: 10 junho 2021). 
Muller, F.; Steinke, A. (2018). ‘Criminalising encounters: MINUSTAH as a laboratory for armed humanitarian pacification'. Global Crime, 19(3-4), p. 228-249.

Neto, M.D. (2019). 'Sobre o patriotismo castrense'. Perseu: Revista do Centro Sérgio Buarque de Holanda da Fundação Perseu Abramo, 18, p. 13-35. Disponível em: https://revistaperseu.fpabramo.org.br/index.php/revista-perseu/article/view/314/256. (Acessado: 16 dezembro 2020).

Oliveira, E.R (1987). 'A doutrina de segurança nacional: pensamento político e projeto estratégico'. in Oliveira, E.R. (ed.). Militares: pensamento e ação política. Campinas: Papirus, 1987, pp. 53-55.

Oliveira, F.R.; Venâncio, B.; Macchia, L. et al. (2019). Forças Armadas e Política Externa no Governo Bolsonaro. Observatório da Política Externa e Inserção Internacional do Brasil. 11 outubro [online]. Disponível em: http://opeb.org/2019/10/11/forcas-armadas-e-politica-externa-no-governo-bolsonaro/. (Acessado: 27 julho 2020).

Oliveiros Ferreira, S. Vida e Morte do Partido Fardado. São Paulo: Editora Senac, 2000. p. 39-96.

Penido, A.; Rodrigues, J.M.; Mathias, S.K. (2020). 'As forças armadas no governo Bolsonaro'. Instituto Tricontinental [online]. Disponível em: https://www.thetricontinental.org/pt-pt/brasil/as-forcas-armadasno-governo-bolsonaro/. (Acessado: 25 julho 2020).

Perlmutter, A. (1969). 'The Praetorian State and the Praetorian Army: Toward a Taxonomy of Civil-Military Relations in Developing Polities'. Comparative Politics, 1(3). p. 382-404.

Pion-Berlin, D. (2012). 'Cumprimento das missões militares na América Latina'. Varia História, 28(48), p. 627643.

Produr, J. (2012). Haiti's New Dictatorship: The Coup, The Earthquake and the UN Occupation. London: Pluto Press, p. 16-26.

Saraiva, M.; Silva, A.V.C. (2019). 'Ideologia e pragmatismo na política externa de Jair Bolsonaro'. Relações Internacionais, 64, pp. 117-137.

Schuberth, M., 2019. Brazilian Peacekeeping? Counterinsurgency and Police Reform in Port-au-Prince and Rio de Janeiro. International Peacekeeping, 26, 487-510. Disponível em: https://doi.org/10.1080/13533312.2019.1623675. (Acessado: 11 novembro 2021).

Silva, G.F.; Paula, L.D. (2017) 'A missão das Nações Unidas para a estabilização do Haiti: uma alternativa para a sucessão de crises?' in Souto; B.C.; Silva, G.F.; Rasquini, G.C. Retrospectiva da Missão das Nações Unidas para a Estabilização do Haiti. Franca: Observatório Sudamericano de Defensa y Fuerzas Armadas, p. $1-4$.

Uziel, E., Marcondes, D., 2021. The Peacekeeping Deployment that Never was: Domestic Considerations Behind Brazil's Decision not to Send Troops to MINUSCA. International Peacekeeping, 28, 757-782. Disponível em: https://doi.org/10.1080/13533312.2021.1975537. (Acessado: 13 novembro 2021).

Verdélio, A. (2019). 'Veja a íntegra do discurso de Bolsonaro na Assembleia Geral da ONU'. Agência Brasil. 24 setembro [online]. Disponível em: https://agenciabrasil.ebc.com.br/politica/noticia/2019-09/presidentejair-bolsonaro-discursa-na-assembleia-geral-da-onu. (Acessado: 12 outubro 2020).

Vidigal, C.E. (2019). ‘Bolsonaro e a reorientação da política exterior brasileira'. Meridiano 47, 20, p. 1-15. Disponível em: https://periodicos.unb.br/index.php/MED/article/view/27792/24440. (Acessado: 12 outubro 2020). 
Zanini, F. (2019). 'Missão no Haiti teve troca de acusações da ONU com polícia local'. Folha de São Paulo. Mundo, 28 maio [online]. Disponível em: https://www1.folha.uol.com.br/mundo/2019/05/missao-no-haititeve-troca-de-acusacoes-da-onu-com-policia-local.shtml. (Acessado: 20 julho 2020).

Zaverucha, J. (2001). 'Militares e participação política no Brasil do final do século XX e início do século XXI'. Revista USP, 39, p. 30-39. 